\title{
Localized Malignant Neoplasm
}

National Cancer Institute

\section{Source}

National Cancer Institute. Localized Malignant Neoplasm. NCI Thesaurus. Code C8576.

A malignant neoplasm which is confined to a specific anatomic site and has not spread to other sites. 